\title{
ИССЛЕДОВАНИЕ ВЛИЯНИЯ ПАРАМЕТРОВ СИСТЕМЫ «СВАЯ-ГРУНТ» НА ДИНАМИЧЕСКИЕ АТРИБУТЫ АКУСТИЧЕСКОГО СИГНАЛА С ИСПОЛЬЗОВАНИЕМ ЧИСЛЕННОГО МОДЕЛИРОВАНИЯ
}

\author{
Чуркин Алексей Андреевич 1 , \\ chaa92@mail.ru
}

\author{
Капустин Владимир Викторович2, \\ 1391854@mail.ru \\ Лозовский Илья Николаевич 3 ,
i.n.lozovsky@yandex.ru
}

Жостков Руслан Александрович4, shageraxcom@yandex.ru

1000 «ЭГЕОС»,

Россия, 117198, г. Москва, ул. Миклухо-Маклая, 8, стр. 3.

2 Московский государственный университет им. М.В. Ломоносова, Россия, 119991, г. Москва, Ленинские горы, 1.

3 Центр геоэлектромагнитных исследований, филиал Института физики Земли им. О.Ю. Шмидта РАН, Россия, 108840, г. Москва, г. Троицк, а/я 30.

4 Институт фризики Земли им. О.Ю. Шмидта РАН, Россия, 123242, г. Москва, ул. Большая Грузинская, 10, стр. 1.

\begin{abstract}
Актуальность исследования обусловлена необходимостью повышения эфффективности применения неразрушающих методов контроля качества свайных фундаментов. Основные направления исследований в данной области сосредоточены на изучении возможностей и ограничений существующих методик контроля и разработке новых, позволяющих получить дополнительные сведения о техническом состоянии конструкций. Надежная оценка сплошности и несущей способности свай, выполненная до ввода фундамента в эксплуатацию, минимизирует последующие риски капитальных затрат на устранение аварийных последствий. Распространенные геофизические методики контроля качества фрундаментов предназначены для изучения состояния материала конструкций. Описанная в публикации модификация сейсмоакустического метода предлагает использовать дополнительную информацию, извлекаемую из акустических сигналов, для сравнительной оценки контактных условий свай. Это позволяет выполнить требования ГОСТ 5686-2012 «Грунты. Методы полевых испьттаний сваями» по выбору характерных мест для проведения статических испьтаний, повысить прогностическую эфрфективность комплекса полевых испытаний в капитальном строительстве.

Цель: изучение изменений динамических атрибутов сигналов, зарегистрированных сейсмоакустическим методом, в зависимости от параметров системы «свая-грунт».

объекты: железобетонные сваи и другие фундаменты глубокого заложения.

Методы: поверхностный сейсмоакустический метод; атрибутный анализ акустических сигналов; численное моделирование процессов распространения упругих волн.

Результаты. Предложена методика сравнительной оценки контактных условий сваи с вмещающим грунтом, основанная на анализе сигналов сейсмоакустического метода с использованием динамических атрибутов нормированной площади спектра и средневзвешенной частоты. Составлено девять серий численных моделей, описывающих характерные системы «сваягрунт». Выполнено трехмерное численное моделирование, для полученных синтетических сигналов рассчитаны атрибуты и построены атрибутные диаграммы. Сделаны выводы о влиянии изменений параметров системы «свая-грунт» на поведение динамических атрибутов отклика.
\end{abstract}

\section{Ключевые слова:}

Испытания свай, сейсмоакустический метод, акустическое излучение, акустический контакт, несущая способность, численное моделирование, неразрушающий контроль.

\section{Введение}

Повышение эффективности использования геофизических методов для изучения природнотехнических систем - актуальный вопрос в области капитального строительства. Изучение взаимодействия фундаментов и вмещающих грунтов затрагивает ряд смежных вопросов: анализ несущей способности и долговечности конструкции, уточнение инфор- мации инженерно-геологических изысканий, оценка экономической рентабельности выбранной технологии производства работ и др.

Для проверки соответствия железобетонных свай характеристикам, заложенным на этапе проектирования, проводят комплекс полевых испытаний. Сплошность бетона и длина свай определяются с применением косвенных геофизических методов [1], а их не- 
сущая способность - в результате проведения более дорогостоящих и трудоемких прямых методов испытаний свай статической или динамической нагрузкой.

В соответствии с требованиями п. 4.4 ГОСТ 56862012 «Грунты. Методы полевых испытаний сваями» места проведения статических испытаний должны быть наиболее характерными для площадки проектируемого свайного фундамента и одна из испытуемых свай должна находиться в месте с предположительно наихудшими грунтовыми условиями.

На практике сведения об инженерногеологических условиях строительной площадки не всегда являются достаточно подробными и достоверными. Кроме того, данный пункт ГОСТ не учитывает возможные отклонения свойств материала и геометрических характеристик изготовленных свай от установленных проектом. Проблемы, вызванные нарушениями контакта свай с вмещающими грунтами, часто невозможно обнаружить вплоть до ввода сооружения в эксплуатацию. Методы контроля за изготовлением конструкции in situ (инклинометрия скважин, лабораторные испытания бетона, надзор за бурением и бетонированием и т. п.) не позволяют упредить возникновение дефектов и снижение адгезии между железобетонным монолитом и грунтом [2].

Большой интерес представляет разработка методики, позволяющей выполнять экспресс-оценку контактных условий и выделять в фундаменте сваи с потенциально сниженной несущей способностью для последующего их испытания прямыми методами.

\section{Поверхностный сейсмоакустический метод} контроля качества свай

Контроль сплошности свай поверхностным сейсмоакустическим методом (low strain impact method, sonic) основан на изучении распространения в теле сваи упругих волн, возбужденных в результате удара молотком по поверхности оголовка. Испытания проводятся оперативно и отличаются небольшим объемом подготовительных работ. Метод позволяет оценить длину конструкции и наличие в её теле значительных дефектов [3].

В 70-х гг. XX в. была предложена модификация сейсмоакустического метода, получившая название метода переходной характеристики/метода устойчивой частотной характеристики (transient response method/steady-state frequency response method) [4, 5]. Методика основана на изучении резонансных явлений, возникающих при возбуждении в свае упругих волн (с использованием вибрационного источника или молотка с регистрирующим силовую характеристику удара тензодатчиком) путем анализа зарегистрированных сигналов в частотной области. Поведение получаемой частотной характеристики, т. н. кривой мобильности/спектра мобильности (mobility spectrum), определяется как параметрами сваи, так и характером ее контакта с вмещающим грунтом [6].

При этом опыт применения метода с целью получения информации о контакте сваи с грунтом выявил значительные ограничения области его применения. Чем больше параметры системы «свая-грунт» отли- чаются от модели «тонкого стержня в однородном полупространстве» (лежащей в основе классической теории сейсмоакустического контроля свай), тем больше возрастает неоднозначность интерпретации данных метода [7].

Предложенная в работе [8] методика оценки контактных условий предлагает рассмотреть распространение акустического сигнала в системе «свая-грунт» с точки зрения поглощения энергии колебаний, количественно характеризуемого набором динамических атрибутов.

\section{Связь контактных условий системы «свая-грунт» и параметров акустического сигнала}

Возможность реализации контроля качества свай поверхностным сейсмоакустическим методом обусловлена повышенной акустической жесткостью материала сваи относительно вмещающего грунта свая является волноводом, по которому распространяется большая часть энергии возбужденных упругих волн. При этом потери энергии сигнала, связанные с излучением колебаний в грунт, зависят как от контраста акустических жесткостей сваи и грунта, так и от свойств контакта между ними [8].

Определим отклик системы «свая-грунт» на ударное воздействие как акустический сигнал $V(t)$, регистрируемый сейсмоприемником в течение временного интервала $\Delta T:\left(0, t_{\mathrm{\kappa}}\right)$. Его спектр Фурье $S(j \omega)$ может быть представлен в виде:

$$
S(j \omega)=A_{\max } \cdot S_{0}(j \omega),
$$

где $A_{\max }$ - максимальная спектральная амплитуда, а $S_{0}(j \omega)$ - спектр, нормированный по величине его максимальной амплитуды.

Возбуждаемые молотками волны имеют малую интенсивность, поэтому поглощение энергии колебаний можно считать линейно зависящим от частоты процессом, на который оказывает пренебрежимо малое воздействие сила удара. Для исследования данных свойств акустического сигнала был проведен ряд полевых экспериментов, результаты которых подтвердили основные положения предлагаемой методики [8]. Тогда для характеристики спектра отклика (1) допустимо пренебречь его амплитудой и анализировать нормированный спектр $S_{0}(j \omega)$, зависящий от свойств колебательной системы и условий возбуждения/регистрации сигнала.

Значительный вклад в отклик вносит техническое состояние оголовка сваи. Массивные арматурные выпуска, шламовый бетон, микротрещины, влияние зоны аэрации на формирующийся материал, изменения сечения в верхней части сваи складываются в т. н. объемный фактор [9]: при возбуждении импульса с широким частотным диапазоном на его параметры оказывает влияние наиболее неоднородная (не считая возможных дефектов) часть конструкции.

Особенностью предложенной методики анализа динамических атрибутов акустических сигналов является анализ относительных изменений их значений и выделение аномальных показателей для свай в составе одного свайного поля. 
Таким образом, область применения поверхностного сейсмоакустического метода для оценки контактных условий ограничена конструкциями, удовлетворяющими следующим требованиям:

1) сваи, изготовленные из бетона одного класса прочности и имеющие одинаковые геометрические параметры;

2) сваи, изготовленные в грунтах, сохраняющих свои свойства по латерали;

3) сваи, в которых не были обнаружены дефекты;

4) сваи с одинаковым состоянием оголовков.

В общем случае для свай, удовлетворяющих перечисленным требованиям, выполняется условие: чем хуже контакт, тем выше энергия отклика. При хорошем контакте сваи с грунтом (рис. $1, a$ ) в возбужденном колебании участвует большая «присоединенная масса» (в которую входит свая и объем грунта, в который излучается акустический сигнал), благодаря этому собственная частота колебательной системы «свая-грунт» снижается [10]. При нарушении контакта (рис. $1, b)$, когда энергия возмущения тратится на отражение и переотражение сигнала внутри исследуемой конструкции, - растет собственная частота колебаний и снижается излучение энергии во внешнюю среду.
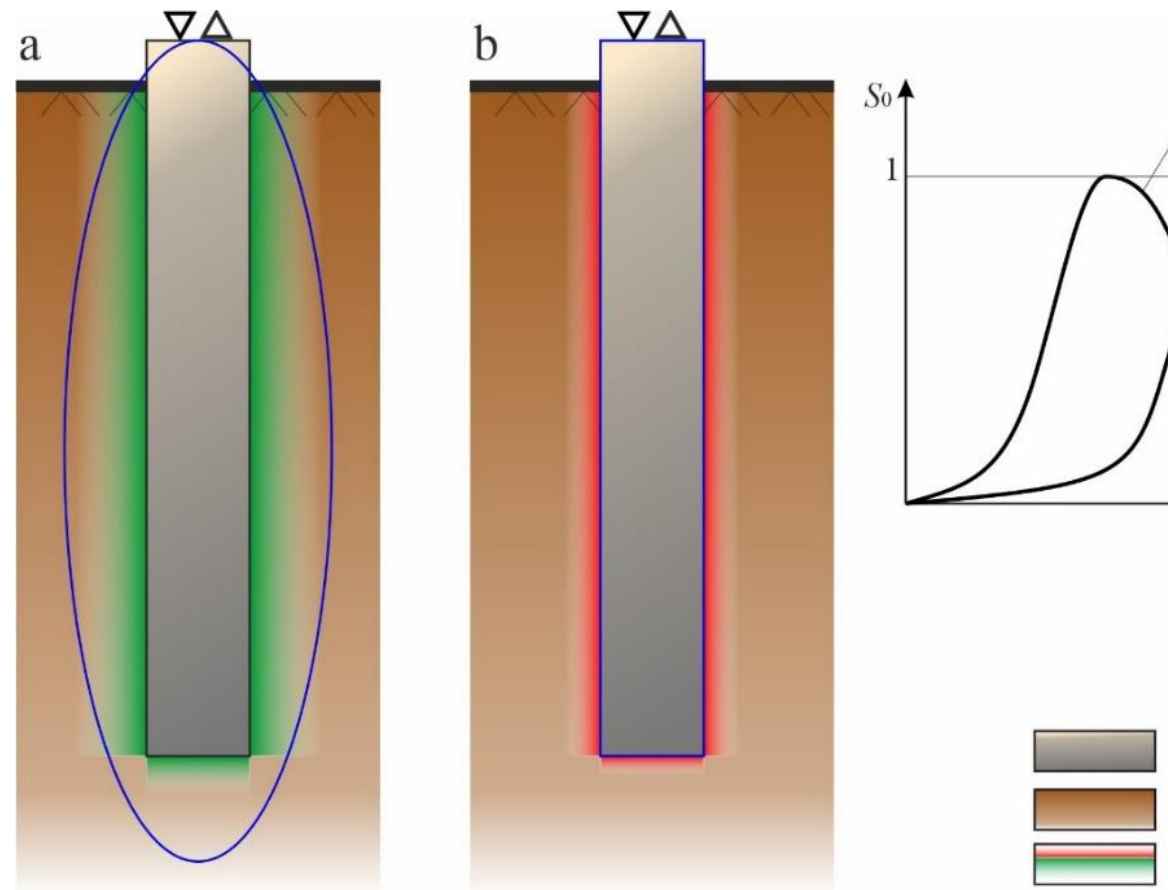

a

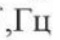

$$
\begin{aligned}
& S_{n \mathrm{a}}<S_{n \mathrm{~b}} \\
& f_{s \mathrm{a}}<f_{s \mathrm{~b}}
\end{aligned}
$$

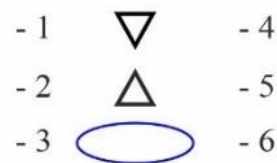

Pис. 1. Общий принцип методики: а) хороший контакт, b) плохой контакт: 1 - бетон; 2 - грунт; 3 - контакт «свая-грунт»; 4 -ударный источник; 5 - приемник; 6 - «присоединенная масса» грунта

Fig. 1. General principle of the technique: a) good contact, b) poor contact: 1 - concrete; 2 - soil; 3 - «pile-soil» contact; 4 -impact source; 5 - receiver; 6 - «attached mass» of soils

Кинетические параметры сигнала, с которыми работает стандартная методика анализа данных сейсмоакустического метода (времена регистрации характерных импульсов на зарегистрированном сигнале), используются для контроля длины и сплошности сваи. Однако они мало чувствительны к изменению физико-механических свойств системы. Динамические параметры (амплитуда и частотный диапазон) сигнала определяются множеством факторов, в которые входят упругие и поглощающие свойства среды, через которую распространяются колебания.

Поэтому для изучения поглощающих свойств системы «свая-грунт» предлагается использовать параметры, численно характеризующие интенсивность и спектральный состав $S_{0}(j \omega)$ - атрибуты площади нормированного спектра $S n$ и средневзвешенной частоты $f_{s}$, связь которых с поглощением акустического сигнала подтверждена на основе большого количества эмпирических данных [11, 12]:

$$
\begin{aligned}
& S n=\sum_{i} S_{0}(i) \cdot d f, \\
& f s=\frac{\sum_{i}(S(i) f(i))}{\sum_{i} S(i)},
\end{aligned}
$$

где $d f=\frac{\Delta f}{2(n-1)}, \Delta f-$ частота дискретизации; $n-$ колво отсчетов в спектре; $i=1,2 \ldots n ; S_{0}(i)-$ значение нормированного спектра в $i$-й точке; $t=0, \ldots t_{k}, f(i)-$ значение частоты в $i$-й точке.

Интерес для практического применения методики представляет изучение поведения атрибутов в зависимости от изменений свойств вмещающих грунтов и формы/материала сваи. Это даст представление об устойчивости предлагаемых сравнительных показателей к изменениям свойств системы «свая-грунт». Для решения данной задачи было выполнено трех- 
мерное численное моделирование распространения упругих волн в сваях для набора характерных, распространенных на практике случаев.

\section{Параметры численных моделей}

В качестве объектов моделирования выбраны бетонные цилиндрические сваи диаметром 0,4 м, длиной 6,0 м. Вмещающие сваю грунты окружены идеально согласованным поглощающим слоем со слабоотражающим условием на внешней границе.

Источник и приемник упругих волн располагались соосно свае на поверхности оголовка и представляли собой круги диаметрами 0,4 и 0,03 м соответственно. Возбуждение сигнала задавалось гауссовым импульсом, модулированным окном Ханнинга. Период импульса источника - 1 мс.

Физические свойства материалов приведены в табл. 1, подбор значений плотности и скорости распространения упругих волн осуществлялся исходя из результатов предыдущих экспериментов по численному моделированию сейсмоакустических методов [13] и справочных значений [14]. Соотношение $V s / V p$ принято равным 0,2 для Грунта 1 и 0,3 для Грунта 2 .

Таблица 1. Свойства материала сваи и изменение свойств вмещуающих грунтов

Table 1. Properties of the pile material and changes in the properties of the enclosing soils

\begin{tabular}{|c|c|c|c|c|c|c|c|c|c|c|}
\hline $\begin{array}{c}\text { Характеристика } \\
\text { Characteristics }\end{array}$ & \multicolumn{5}{|c|}{$\begin{array}{c}\text { Бетон } \\
\text { Concrete }\end{array}$} & \multicolumn{5}{|c|}{$\begin{array}{l}\text { Шлам } \\
\text { Sludge }\end{array}$} \\
\hline $\begin{array}{l}\text { Плотность, } \rho, \text { кг/} \mathrm{m}^{3} \\
\text { Density, } \mathrm{kg} / \mathrm{m}^{3}\end{array}$ & \multicolumn{5}{|c|}{2300} & \multicolumn{5}{|c|}{2000} \\
\hline $\begin{array}{l}\text { Скорости } V p \text { и } V s, \text { м/с } \\
\text { P-wave }(V p) \text { and } \mathrm{S} \text {-wave }(V s) \text { velocity, } \mathrm{m} / \mathrm{s}\end{array}$ & \multicolumn{5}{|c|}{$4000 ; 2442$} & \multicolumn{5}{|c|}{$2800 ; 1350$} \\
\hline \multicolumn{11}{|c|}{ Грунт 1/Soil 1} \\
\hline $\begin{array}{l}\text { № модели в серии } \\
\text { Model no. }\end{array}$ & $* .1$ & $* .2$ & $* .3$ & $* .4$ & $* .5$ & $* .6$ & $* .7$ & $* .8$ & $* .9$ & $* .10$ \\
\hline $\begin{array}{l}\text { Плотность, } \rho, \text { кг/ }{ }^{3} \\
\text { Density, } \mathrm{kg} / \mathrm{m}^{3}\end{array}$ & 1500 & 1500 & 1550 & 1550 & 1600 & 1600 & 1650 & 1650 & 1700 & 1700 \\
\hline $\begin{array}{l}\text { Скорости } V p \text { и } V s, \text { м/с } \\
\text { P-wave }(V p) \text { and } \mathrm{S} \text {-wave }(V s) \text { velocity, } \mathrm{m} / \mathrm{s}\end{array}$ & $\begin{array}{l}600 \\
120\end{array}$ & $\begin{array}{l}720 \\
144\end{array}$ & $\begin{array}{l}840 \\
168\end{array}$ & $\begin{array}{l}960 \\
192\end{array}$ & $\begin{array}{c}1080 \\
216\end{array}$ & $\begin{array}{c}1200 \\
240\end{array}$ & $\begin{array}{c}1320 \\
264\end{array}$ & $\begin{array}{c}1440 \\
288\end{array}$ & $\begin{array}{c}1560 \\
312\end{array}$ & $\begin{array}{c}1680 \\
336\end{array}$ \\
\hline \multicolumn{11}{|c|}{ Грунт 2/Soil 2} \\
\hline $\begin{array}{l}\text { Плотность, } \rho, \text { кг/ } \mathrm{m}^{3} \\
\text { Density, } \mathrm{kg} / \mathrm{m}^{3}\end{array}$ & 2200 & 2200 & 2250 & 2250 & 2300 & 2300 & 2350 & 2350 & 2400 & 2400 \\
\hline $\begin{array}{l}\text { Скорости } V p \text { и } V s, \text { м/с } \\
\text { P-wave }(V p) \text { and } \mathrm{S} \text {-wave }(V s) \text { velocity, } \mathrm{m} / \mathrm{s}\end{array}$ & $\begin{array}{c}2700 \\
810\end{array}$ & $\begin{array}{c}2835 \\
850\end{array}$ & $\begin{array}{c}2970 \\
890\end{array}$ & $\begin{array}{c}3105 \\
930\end{array}$ & $\begin{array}{c}3240 \\
970\end{array}$ & $\begin{array}{l}3375 \\
1010\end{array}$ & $\begin{array}{c}3510 \\
1050\end{array}$ & $\begin{array}{c}3645 \\
1090\end{array}$ & $\begin{array}{l}3780 \\
1130\end{array}$ & $\begin{array}{c}3915 \\
1170\end{array}$ \\
\hline
\end{tabular}

С учетом международного опыта численного моделирования сейсмоакустического метода [15-17] было принято решение не учитывать затухание сигнала в материале сваи и во вмещающих грунтах, так как для поставленной задачи принципиален не характер поглощения энергии сигнала в грунте, а потери энергии на излучение из сваи в грунт, определяющиеся контрастом акустических жесткостей и контактными условиями.

Численные модели были разделены на 4 группы (рис. 2).

Группа 1. Свая без дефекта (1.1) и свая с дефектом (1.2) в однородном грунте.

Свая погружена в Грунт 1, контраст акустических жесткостей сваи и грунта плавно снижается от модели к модели (табл. 2). В качестве дефекта в серии моделей 1.2 задано сужение ствола сваи до половины площади ее поперечного сечения в пределах отметок 2-3 м (относительно верха сваи).
Группа 2. Свая, опирающаяся на плотные грунты (2.1), и свая, пересекающая слой плотных грунтов (2.2).

Модель 2.1 представляет сваю во вмещающем Грунте 1.1, нижний торец которой заглублен в залегающий ниже Грунт 2 на 0,3 м. Свойства Грунта 2 плавно меняются, его акустическая жесткость приближается к значению акустической жесткости бетона сваи (табл. 2). В модели 2.2 свая последовательно прорезает три геологических слоя: Грунт 1.1, Грунт 2 (в пределах отметок 2-4 м относительно верха сваи) и Грунт 1.1.

Группа 3. Свая с уширением (3.1) и шламовым слоем (3.2) в верхней части.

В моделях 3.1 и 3.2 свая погружена в Грунт 1. В модели 3.1 верхний метр сваи имеет диаметр 0,6 м в 1,5 раза больше номинального диаметра. В модели 3.2 верхние 0,4 м сваи представлены не бетоном, а шламовым материалом.

Таблица 2. Отношение акустических жесткостей материала сваи и вмещзающих грунтов

Table 2. Ratio of acoustic stiffness of the pile material and enclosing soils

\begin{tabular}{|c|c|c|c|c|c|c|c|c|c|c|}
\hline $\begin{array}{c}\text { № модели в серии } \\
\text { Model по. in series }\end{array}$ & $* .1$ & $* .2$ & $* .3$ & $* .4$ & $* .5$ & $* .6$ & $* .7$ & $* .8$ & $* .9$ & $* .10$ \\
\hline$\frac{\rho_{\text {св }} \cdot V p_{\text {св }}}{\rho_{\text {гр1 }} \cdot V p_{\text {гр1 }}}$ & 10,2 & 8,5 & 7,1 & 6,2 & 5,3 & 4,8 & 4,2 & 3,9 & 3,5 & 3,2 \\
\hline$\frac{\rho_{\text {св }} \cdot V p_{\text {св }}}{\rho_{\text {гр2 } 2} \cdot V p_{\text {гр } 2}}$ & 1,5 & 1,5 & 1,4 & 1,3 & 1,2 & 1,2 & 1,1 & 1,1 & 1,0 & 1,0 \\
\hline
\end{tabular}




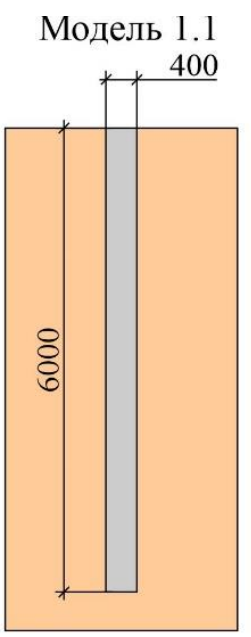

Модель 1.2

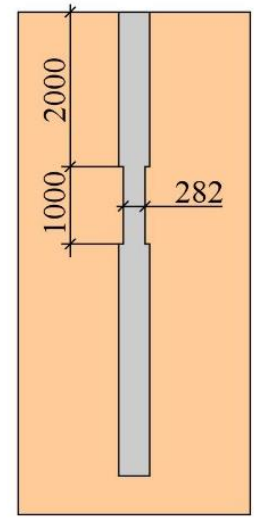

Модель 2.1

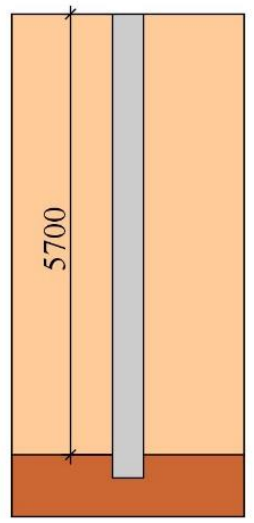

Модель 2.2

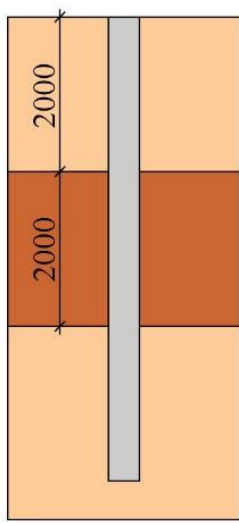

Модель 3.1

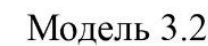

Модель 4.1

Модель 4.2

Модель 4.3
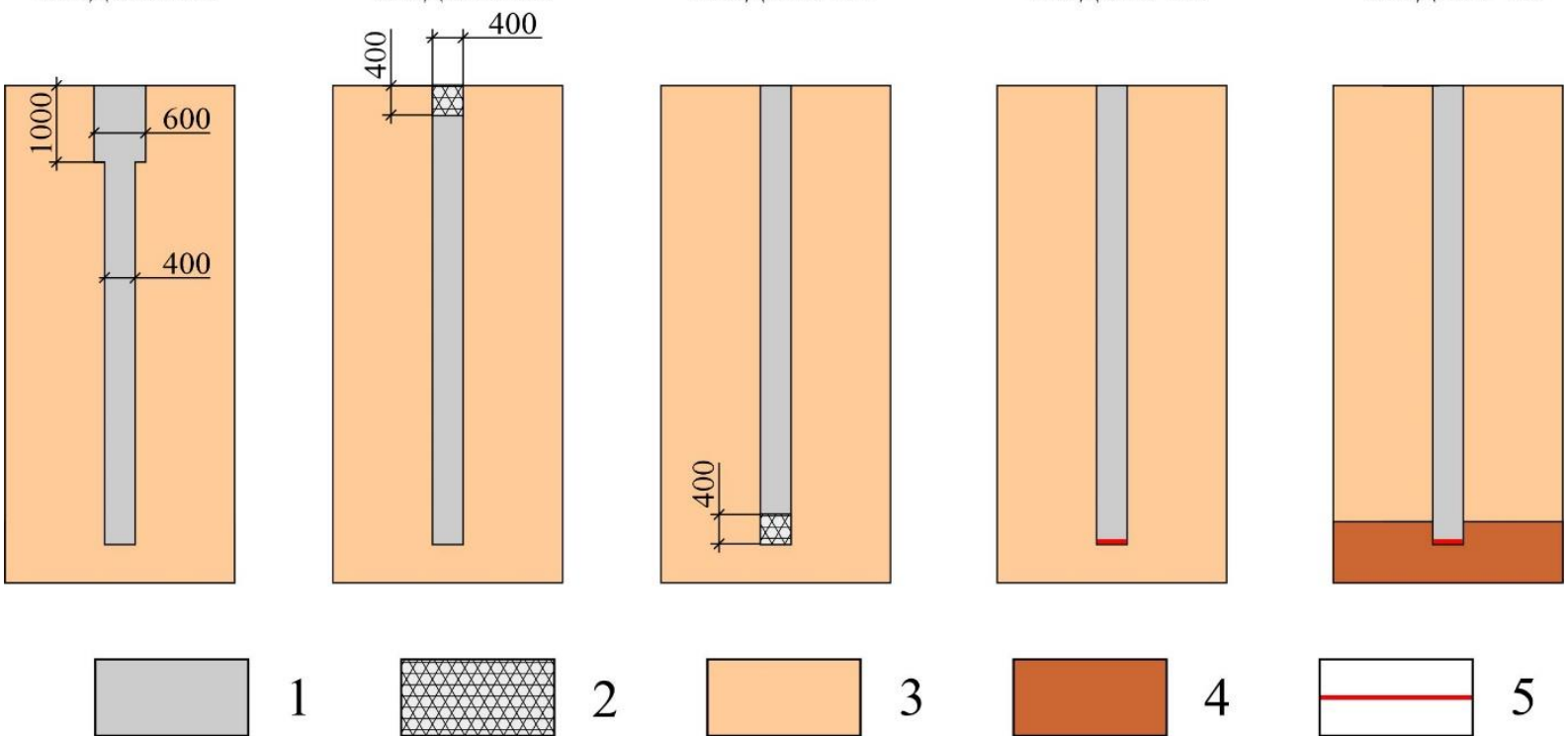

\section{2}

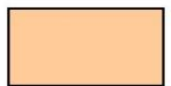

3

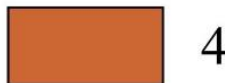

4

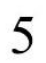

Рис. 2. Схемы моделей (размеры даны в миллиметрах): 1 - бетон; 2 - илам; 3 - Грунт 1; 4 - Грунт 2; 5 - отражаюшиая граница

Fig. 2. Model schemes (dimensions are given in millimeters): 1 -concrete; 2 - sludge; 3 - Soil 1; 4 - Soil 2; 5 - reflective boundary

Группа 4. Свая с дефектом у ее забоя (4.1) и свая с нарушением контакта по нижнему ториу, опирающзаяся на слабый (4.2) или плотный грунт (4.3).

В сериях моделей 4.1 и 4.2 свая находится во вмещающем Грунте 1. Модель 4.1 симулирует дефект «слабого основания»/«soft bottom» $[18,19]$, моделируемый с помощью шламового материала у нижнего конца сваи мощностью 0,4 м. Модель 4.2 имитирует случай нарушения контакта, возникающий при «полировке» забоя скважины буровым инструментом [20]. «Полированный забой» имитируется за счет полностью отражающей границы между нижним торцом сваи и грунтом. Модель 4.3 повторяет параметры модели 2.1 с добавлением полностью отражающей границы на нижний торец сваи.

\section{Результаты моделирования}

Трехмерное численное моделирование методом конечных элементов выполнено в программном ком- плексе COMSOL Multiphysics 5.4 (модули Structural Mechanics и Acoustics, лицензия № 9600341). Результаты представлены в виде графиков зависимости вертикальной компоненты скорости смещения частиц оголовка сваи от времени (рис. 3). Для полученных синтетических сигналов по формулам (2) и (3) рассчитаны динамические атрибуты. На рис. 4 представлены значения атрибутов в зависимости от номера модели в серии. Абсолютные значения атрибутов изменяются нелинейно с изменением акустических свойств вмещающих грунтов.

Представленные результаты позволяют наглядно проиллюстрировать положение о большей чувствительности динамических параметров к изменениям физико-механических свойств среды, нежели кинетических (табл. 3).

Изменения формы сигнала, приводящие к незначительному разбросу определяемых времен прихода целевых отраженных импульсов (от нижнего конца 
сваи, дефектов сечения, геологических границ), не превышающему первых процентов, наблюдаются для моделей с обладающим высокой акустической жесткостью Грунтом 2. Для сигналов, полученных при ва-

1.1

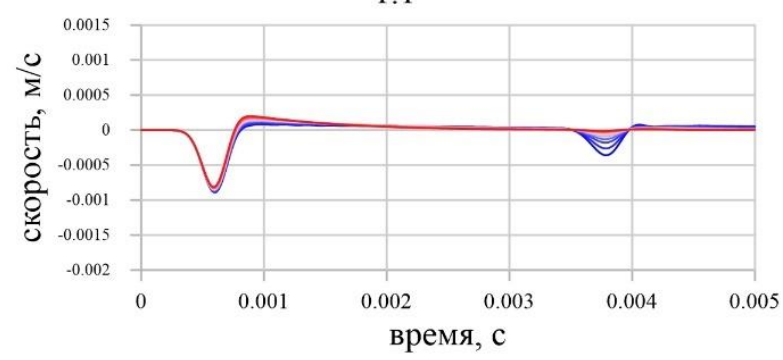

1.2

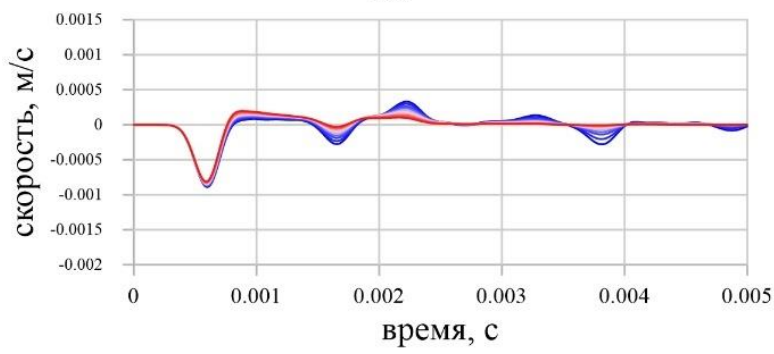

2.1

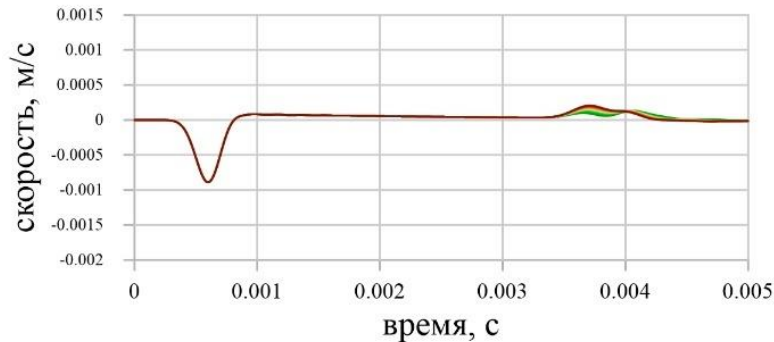

2.2

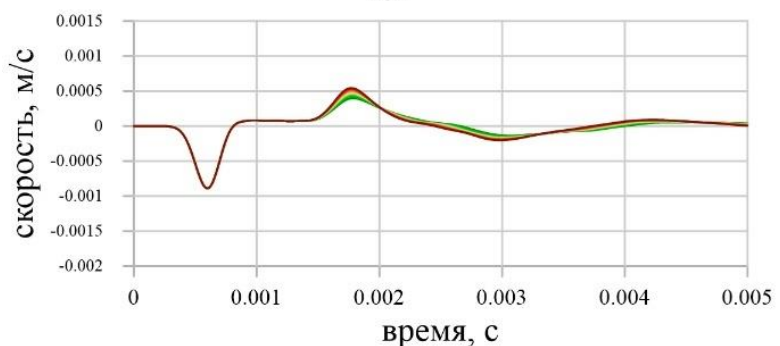

время, с

Изменение свойств Грунта 1 (плотность $\rho$, скорость $V p$, скорость $V s$ ):

$-1500 \mathrm{Kr} / \mathrm{M}^{3}, 600 \mathrm{M} / \mathrm{c}, 120 \mathrm{M} / \mathrm{c} \longrightarrow 1600 \mathrm{Kr} / \mathrm{M}^{3}, 1200 \mathrm{M} / \mathrm{c}, 240 \mathrm{M} / \mathrm{c}$

$-1500 \mathrm{Kr} / \mathrm{M}^{3}, 720 \mathrm{M} / \mathrm{c}, 144 \mathrm{M} / \mathrm{c} \longrightarrow 1650 \mathrm{Kr} / \mathrm{M}^{3}, 1320 \mathrm{M} / \mathrm{c}, 264 \mathrm{M} / \mathrm{c}$

$-1550 \mathrm{Kr} / \mathrm{M}^{3}, 840 \mathrm{M} / \mathrm{c}, 168 \mathrm{M} / \mathrm{c}-1650 \mathrm{Kr} / \mathrm{M}^{3}, 1440 \mathrm{M} / \mathrm{c}, 288 \mathrm{M} / \mathrm{c}$

$-1550 \mathrm{Kr} / \mathrm{M}^{3}, 960 \mathrm{M} / \mathrm{c}, 192 \mathrm{M} / \mathrm{c}-1700 \mathrm{Kr} / \mathrm{M}^{3}, 1560 \mathrm{M} / \mathrm{c}, 312 \mathrm{M} / \mathrm{c}$

$-1600 \mathrm{Kr} / \mathrm{M}^{3}, 1080 \mathrm{M} / \mathrm{c}, 216 \mathrm{M} / \mathrm{c}-1700 \mathrm{Kr} / \mathrm{M}^{3}, 1680 \mathrm{M} / \mathrm{c}, 336 \mathrm{M} / \mathrm{c}$

Изменение свойств Грунта 2 (плотность $\rho$, скорость $V p$, скорость $V s$ ):

$-2200 \mathrm{Kr} / \mathrm{M}^{3}, 2700 \mathrm{M} / \mathrm{c}, 810 \mathrm{M} / \mathrm{c} \longrightarrow 2300 \mathrm{Kr} / \mathrm{M}^{3}, 3375 \mathrm{M} / \mathrm{c}, 1010 \mathrm{M} / \mathrm{c}$

$-2200 \mathrm{Kr} / \mathrm{M}^{3}, 2835 \mathrm{M} / \mathrm{c}, 850 \mathrm{M} / \mathrm{c} \longrightarrow 2350 \mathrm{Kr} / \mathrm{M}^{3}, 3510 \mathrm{M} / \mathrm{c}, 1050 \mathrm{M} / \mathrm{c}$

$-2250 \mathrm{Kr} / \mathrm{M}^{3}, 2970 \mathrm{M} / \mathrm{c}, 890 \mathrm{M} / \mathrm{c}-2350 \mathrm{Kr} / \mathrm{M}^{3}, 3645 \mathrm{M} / \mathrm{c}, 1090 \mathrm{M} / \mathrm{c}$

$-2250 \mathrm{Kr} / \mathrm{M}^{3}, 3105 \mathrm{M} / \mathrm{c}, 930 \mathrm{M} / \mathrm{c} \longrightarrow 2400 \mathrm{Kr} / \mathrm{M}^{3}, 3780 \mathrm{M} / \mathrm{c}, 1130 \mathrm{M} / \mathrm{c}$

$2300 \mathrm{Kr} / \mathrm{M}^{3}, 3240 \mathrm{M} / \mathrm{c}, 970 \mathrm{M} / \mathrm{c}-2400 \mathrm{\kappa r} / \mathrm{M}^{3}, 3915 \mathrm{M} / \mathrm{c}, 1170 \mathrm{M} / \mathrm{c}$ рьировании характеристик Грунта 1, заметные изменения кинематических параметров отсутствуют, в отличие от значений динамических атрибутов, относительные изменения которых достигают $20 \%$.

3.1

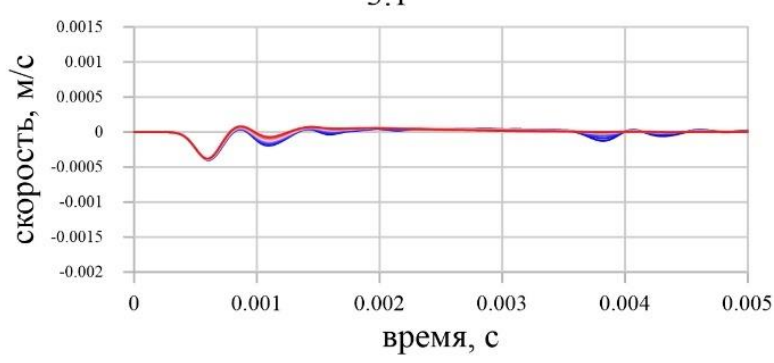

3.2

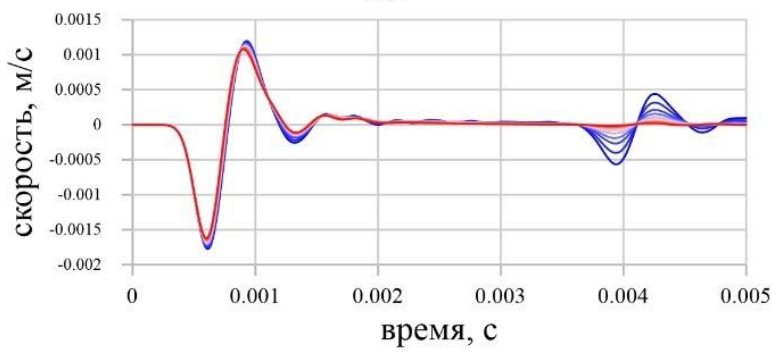

4.1

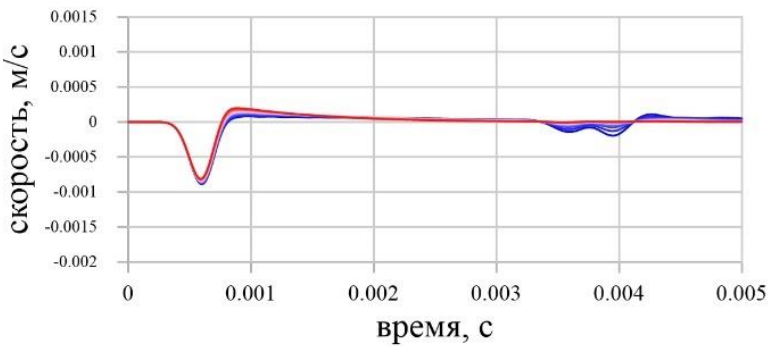

4.2

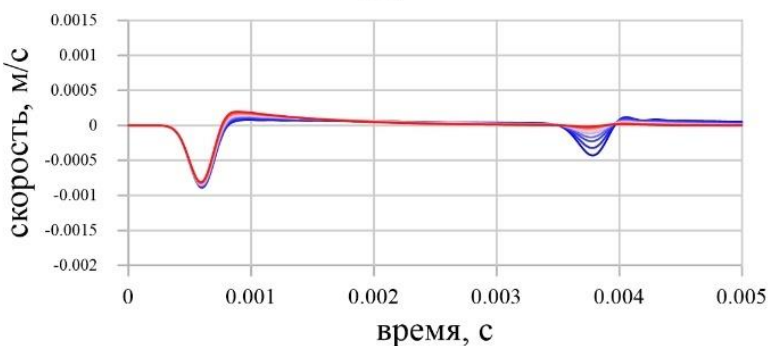

4.3

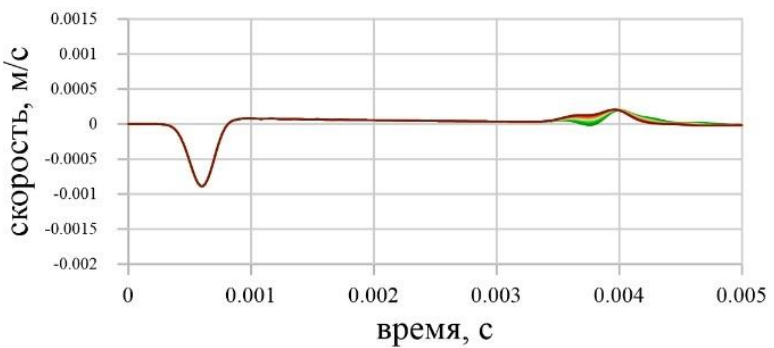

Рис. 3. Синтетические сигналы, полученные в результате моделирования

Fig. 3. Synthetic signals obtained as a result of numerical simulation 
Таблица 3. Изменение кинематических и динамических параметров сигналов в зависимости от свойств вмещающих грунтов

Table 3. Kinematic and dynamic parameters of signals depending on soil properties

\begin{tabular}{|c|c|c|c|c|c|c|}
\hline $\begin{array}{c}\text { Серия моделей } \\
\text { Model series }\end{array}$ & \multicolumn{3}{|l|}{1.1} & \multicolumn{3}{|l|}{2.2} \\
\hline $\begin{array}{l}\text { Параметр } \\
\text { Parameter }\end{array}$ & $\begin{array}{c}\text { Отражение от нижнего } \\
\text { конца сваи, мc } \\
\text { Refraction from pile toe, ms }\end{array}$ & Sn & $\begin{array}{c}f \mathrm{~s}, \Gamma \amalg \\
\mathrm{Hz}\end{array}$ & $\begin{array}{c}\text { Отражение от верхней границы } \\
\text { Грунта 2, мс } \\
\text { Refraction from Soil } 2 \text { upper boundary, ms }\end{array}$ & $S n$ & $\begin{array}{c}f S, \Gamma \amalg \\
\mathrm{Hz}\end{array}$ \\
\hline$* .1$ & 3,79 & 1355 & 3148 & 1,80 & 944 & 2548 \\
\hline$* .2$ & 3,79 & 1488 & 3114 & 1,80 & 942 & 2555 \\
\hline$* .3$ & 3,79 & 1637 & 2974 & 1,80 & 942 & 2562 \\
\hline$* .4$ & 3,79 & 1745 & 2875 & 1,79 & 928 & 2568 \\
\hline$* .5$ & 3,79 & 1866 & 2793 & 1,79 & 903 & 2575 \\
\hline$* .6$ & 3,78 & 1927 & 2762 & 1,78 & 886 & 2581 \\
\hline$* .7$ & 3,78 & 1977 & 2751 & 1,78 & 866 & 2587 \\
\hline$* .8$ & 3,78 & 2007 & 2776 & 1,78 & 852 & 2591 \\
\hline$* .9$ & 3,78 & 2037 & 2803 & 1,77 & 837 & 2598 \\
\hline$* .10$ & 3,78 & 2054 & 2823 & 1,77 & 826 & 2602 \\
\hline $\begin{array}{c}\text { Коэффициент вариации } \\
\text { Coefficient of variation Cv, \% }\end{array}$ & 0 & 14 & 5 & 1 & 5 & 1 \\
\hline
\end{tabular}
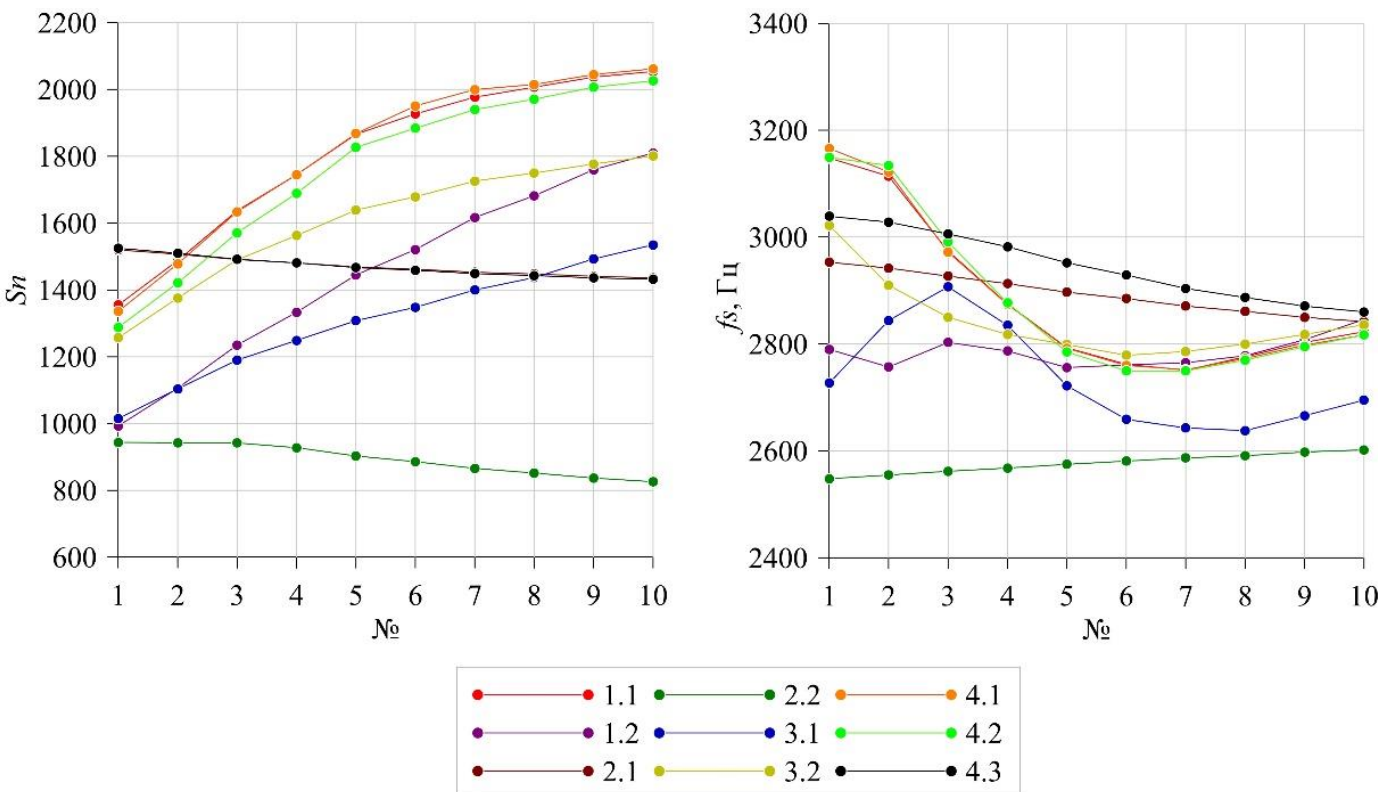

Pис. 4. Значения динамических атрибутов для наборов численных моделей

Fig. 4. Dynamic attributes for numerical model series

\section{Обсуждение результатов моделирования}

Выделим несколько групп моделей, исходя из их особенностей и наблюдаемого поведения атрибутов. Изменение отклика иллюстрируется с помощью корреляционных диаграмм $(S n ; f s)$, наиболее представительных для анализа поглощения в системе «сваягрунт». Серия моделей 1.1 присутствует во всех группах для сравнения атрибутов с показателями модели, наиболее приближенной к случаю «тонкого стержня в однородном полупространстве», лежащему в основе классической теории сейсмоакустического метода.

1. Сваи с изменяющейся площзадью излучающей поверхности (серии 1.1, 1.2, 3.1).

Поведение атрибутов (рис. 5, a) соответствует теоретическому представлению - нормированная площадь спектра $S n$ для свай с сужением и уширением сечения снижена относительно $S n_{1.1}$ на 25-30 \% для сваи с уширением оголовка и на 20-25 \% для сваи с сужением ствола (табл. 4). Разница в значениях средневзвешенной частоты $f s$ снижается по мере увеличения акустической жесткости вмещающего грунта. Для серии моделей 3.1 нормированная площадь спектра значительно снижена относительно модели 1.1 вне зависимости от значений $\rho_{\text {гр1 }} \cdot V p_{\text {гр1 }}$.

Изменение сечения в верхней части конструкции влияет на атрибуты отклика сильнее изменения сечения, заданного на удалении от оголовка, и меньше зависит от акустических свойств вмещающего грунта.

2. Сваи, изготовленные в разрезе с плотныли грунтами (серии 1.1, 2.1, 2.2).

Динамический отклик сваи, опирающейся на (модель 2.1) или пересекающей (модель 2.2) слой плотных грунтов, ведет себя принципиально иначе (рис. 5, b), чем отклик сваи, расположенной в контрастном по акустическим свойствам грунте. Акустическая жесткость Грунта 2 изменяется вплоть до совпадения с акустической жесткостью материала сваи - это соот- 
ветствует практическим случаям сваи, опирающейся на скальные грунты (для модели 2.1), или сваи, устроенной в геологическом разрезе с чередованием слоев с различными прочностными характеристиками, например в моренных отложениях (для модели 2.2).

Абсолютные значения атрибутов отклика для серий 2.1 и 2.2 меняются незначительно (табл. 5) можно сделать вывод о том, что в случае заделки свай в плотные грунты динамические параметры сигнала устойчивы к плавным изменениям свойств данных грунтов.

3. Сваи со шламовым слоем (изменением свойств материала сваи) (серии 1.1, 3.2, 4.1).

Поведение отклика серий 1.1 и 4.1 практически не отличается - слой шлама у основания не оказал заметного влияния на абсолютные значения атрибутов (рис. 5, c). Это можно связать с тем, что основной вклад в затухание энергии даже в случае моделей се- рии 1.1 дает излучение через боковую поверхность сваи во внешнюю среду. На малый по площади поверхности нижний торец приходится незначительная часть излучения. Превышающее ожидания излучение свай через боковую поверхность может указывать на недостатки используемых параметров моделирования и требует дополнительных уточнений.

Тем не менее малое изменение свойств основания конструкции, погруженной в контрастные по акустическим свойствам грунты, не оказало заметного влияния на поведение отклика, которое можно было бы выделить на фоне изменений свойств грунта.

Поведение атрибутов в моделях со шламовым материалом в оголовке (серия 3.2) схоже с их поведением в моделях с уширением сечения в верхней части снижение $S n$ и уменьшающаяся по мере роста $\rho_{\text {гр1 }} \cdot V p_{\text {гр1 }}$ разница средневзвешенных частот $f_{s_{3.2}}$ и $f_{s_{1.1}}$ (табл. 4).

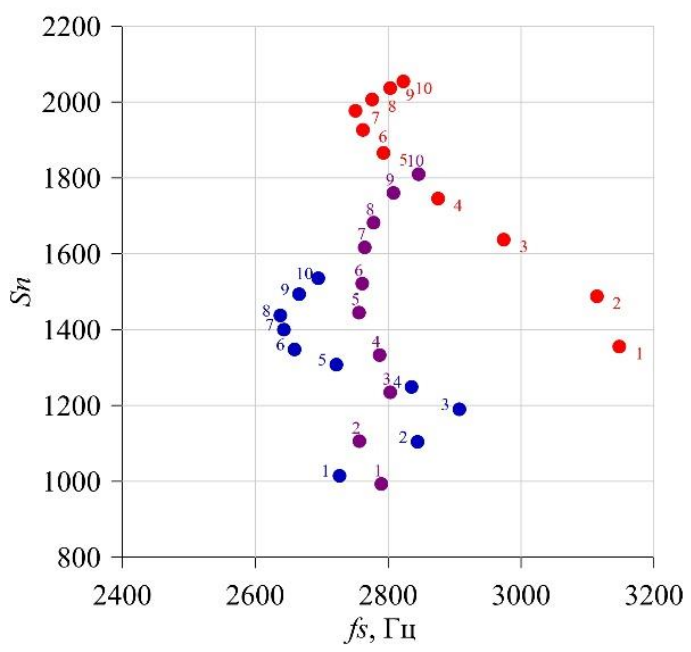

$\mathrm{c}$

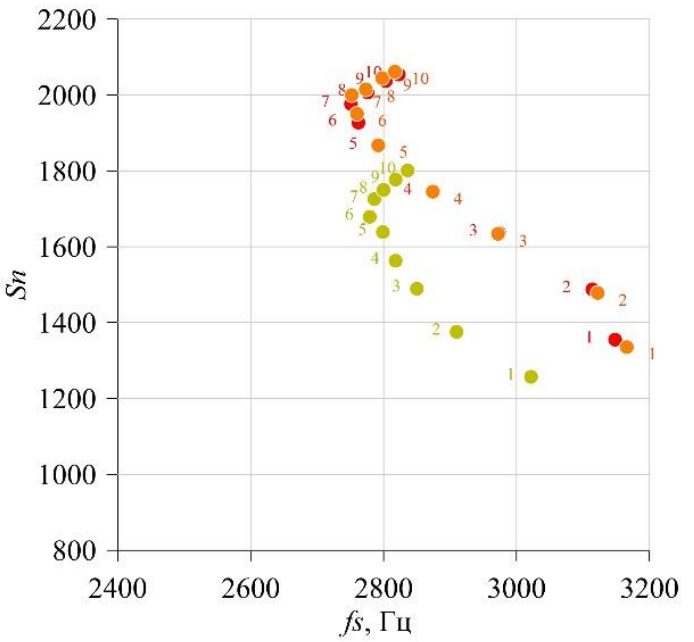

$\mathrm{b}$

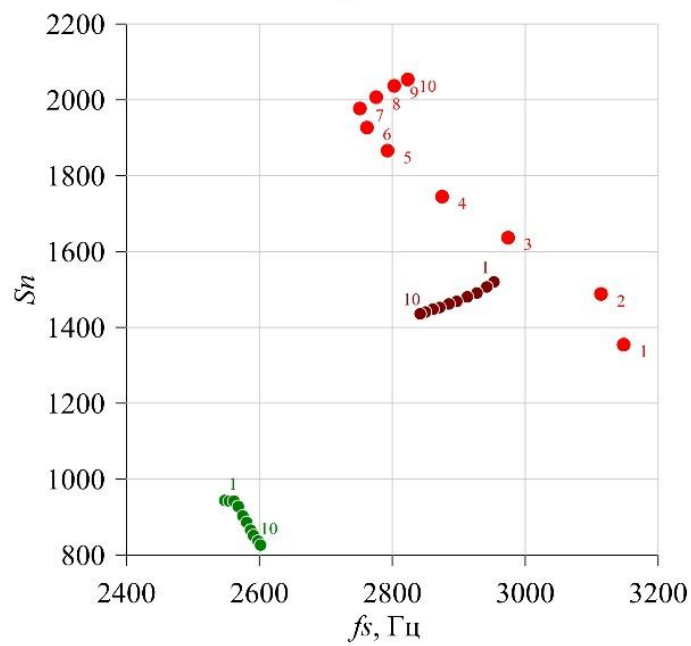

d

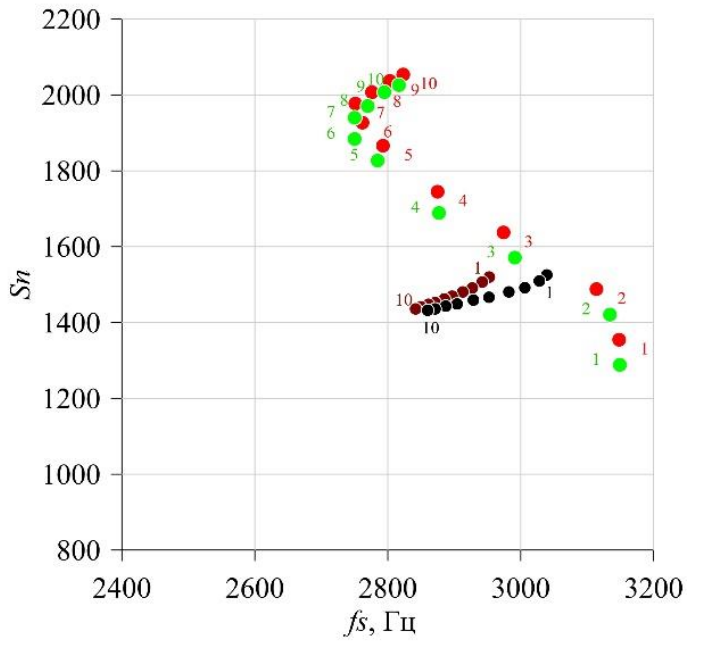

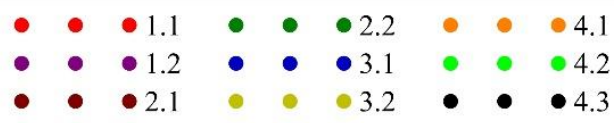

Pис. 5. Атрибутные диаграммы для серий численных моделей

Fig. 5. Attribute charts for numerical model series 
Можно сделать вывод, что неоднородности в верхней части сваи, независимо от их физической природы (изменение геометрии или свойств бетона), действуют на отклик в качестве кажущегося «улучшения контакта», т. е. работают в качества «демпфера» для ударного импульса.

4. Сваи с нарушением контакта по нижнему ториу (серии 1.1, 2.1, 4.2, 4.3).

Наличие полностью отражающей границы симулирует ухудшение контактных условий, которое может быть вызвано обводнением грунта основания или «полировкой» забоя буровым инструментом $[18,20]$.

Сравнение атрибутов для серий 1.1 и 4.2 (рис. 5, $d$ ) показывает, что нарушение контакта не оказало заметного влияния на поведение отклика сваи, погруженной в контрастный по акустическим свойствам грунт. Это может быть объяснено приведенными выше соображениями о полученном по данным моделирования большем влиянии излучения через боковую поверхность на значения атрибутов.

По поведению атрибутов серий 2.1 и 4.3 можно сделать вывод, что при заделке основания сваи в «скальные» грунты дефект контакта по торцу более выражен, чем при заделке в «рыхлые» грунты. При практически неизменной $S n$ значения $f s$ заметно от-

личаются (разница снижается по мере увеличения акустической жесткости Грунта 2), в сравнении с более стабильным поведением атрибутов для серий моделей 2.1 и 2.2 .

При заделке сваи в плотные грунты плохой контакт основания влияет на поведение атрибута средневзвешенной частоты сильнее малых изменений свойств грунта, однако это различие выражено в случаях, когда грунт основания имеет меньшую акустическую жесткость в сравнении с бетоном сваи.

Таблица 4. Соотномение атрибутов серий 1.2, 3.1, 3.2 с серией 1.1

Table 4. Ratio of attributes of series 1.2, 3.1, 3.2 with series 1.1

\begin{tabular}{|c|c|c|c|c|c|c|}
\hline № & $S n_{1.2} / S n_{1.1}$ & $f s_{1.2} / f s_{1.1}$ & $S n_{3.1} / S n_{1.1}$ & $f s_{3.1} / f s_{1.1}$ & $S n_{3.2} / S n_{1.1}$ & $f s_{3.2} / f s_{1.1}$ \\
\hline *.1 & 0,73 & 0,89 & 0,75 & 0,87 & 0,93 & 0,96 \\
\hline *.2 & 0,74 & 0,89 & 0,74 & 0,91 & 0,92 & 0,93 \\
\hline$* .3$ & 0,75 & 0,94 & 0,73 & 0,98 & 0,91 & 0,96 \\
\hline$* .4$ & 0,76 & 0,97 & 0,72 & 0,99 & 0,90 & 0,98 \\
\hline$* .5$ & 0,77 & 0,99 & 0,70 & 0,97 & 0,88 & 1,00 \\
\hline$* .6$ & 0,79 & 1,00 & 0,70 & 0,96 & 0,87 & 1,01 \\
\hline$* .7$ & 0,82 & 1,01 & 0,71 & 0,96 & 0,87 & 1,01 \\
\hline$* .8$ & 0,84 & 1,00 & 0,72 & 0,95 & 0,87 & 1,01 \\
\hline$* .9$ & 0,86 & 1,00 & 0,73 & 0,95 & 0,87 & 1,01 \\
\hline$* .10$ & 0,88 & 1,01 & 0,75 & 0,95 & 0,88 & 1,00 \\
\hline
\end{tabular}

Таблица 5. Коэффициенты вариаџии Сv атрибутов Sn и fs, \%

Table 5. Coefficients of variation $C v$ of attributes Sn and $f s$, \%

\begin{tabular}{|c|c|c|c|c|c|c|c|c|c|c|c|c|c|c|c|c|c|c|c|}
\hline $\begin{array}{c}\text { Серия } \\
\text { Series }\end{array}$ & \multicolumn{2}{|c|}{1.1} & \multicolumn{2}{|c|}{1.2} & \multicolumn{2}{|c|}{2.1} & \multicolumn{2}{|c|}{2.2} & \multicolumn{2}{|c|}{3.1} & \multicolumn{2}{|c|}{3.2} & \multicolumn{2}{|c|}{4.1} & \multicolumn{2}{|c|}{4.2} & \multicolumn{2}{c|}{4.3} \\
\hline $\begin{array}{c}\text { Атрибут } \\
\text { Attribute }\end{array}$ & $S n$ & $f s$ & $S n$ & $f s$ & $S n$ & $f s$ & $S n$ & $f s$ & $S n$ & $f s$ & $S n$ & $f s$ & $S n$ & $f s$ & $S n$ & $f s$ & $S n$ & $f s$ \\
\hline $\mathrm{Cv}$ & 14 & 5 & 19 & 1 & 2 & 1 & 5 & 1 & 13 & 3 & 11 & 3 & 14 & 5 & 15 & 5 & 2 & 2 \\
\hline
\end{tabular}

\section{Выводы}

Результаты выполненного моделирования можно обобщить в нескольких наблюдениях:

1. Наглядно показана чувствительность динамических параметров акустического сигнала к изменению физико-механических свойств изучаемой колебательной системы (акустических свойств вмещающих грунтов и контактных условий). При этом кинематические параметры сигнала не изменяются или изменяются очень слабо.

2. Излучение через боковую поверхность и, следовательно, контактные условия по боковой поверхности влияют на поведение атрибутов отклика сильнее, чем излучение через нижний торец сваи.

3. Неоднородности в верхней части сваи так же, как и сужение ее поперечного сечения, приводят к изменению атрибутов отклика, интерпретируемому в качестве кажущегося улучшения контактных условий, вне зависимости от характера неоднородности.

\section{СПИСОК ЛИТЕРАТУРЫ}

1. О техническом регулировании неразрушающего контроля сплошности свай / А.А. Мухин, В.В. Капустин, А.А. Чуркин, И.Н. Лозовский // Геотехника. - 2019. - Т. 11. № 2. - С. 80-89.

2. Мангушев Р.А., Пономарев А.Б. К вопросу контроля качества изготовления и приемки буронабивных свай // Вестник Перм-
4. При наличии в геологическом разрезе слоя плотных грунтов динамические параметры сигнала становятся устойчивыми к плавным изменениям акустических свойств вмещающих грунтов.

5. В случае опирания сваи на слой плотных грунтов атрибут средневзвешенной частоты более чувствителен к нарушению контактных условий, чем атрибут нормированной площади спектра.

Дальнейшее усложнение моделей (частичное или полное нарушение контактных условий по боковой поверхности и т. п.) позволит продолжить изучение зависимости динамических параметров сигнала от характеристик системы «свая-грунт».

Полученные по результатам моделирования выводы удовлетворяют общим теоретическим представлениям о распространении акустических волн в сваях и ограничениях предлагаемой методики, но нуждаются в проверке результатами полевых испытаний, сопровождающихся использованием прямых методов контроля.

ского национального исследовательского политехнического университета. Строительство и архитектура. - 2014. - № 3. C. 88-111.

3. Возможности сейсмоакустических и ультразвуковых методов при контроле качества свайных фундаментов / В.В. Капустин, А.А. Чуркин, И.Н. Лозовский, А.В. Кувалдин // Геотехника. 2018. - T. 10. - № 5-6. - C. 62-71. 
4. Davis A.G., Dunn C.S. From theory to field experience with the non-destructive vibration testing of piles // Proceedings of the Institution of Civil Engineers. - 1974. - V. 57. - P. 571-593.

5. Chan H.F.C. Non-destructive testing of concrete piles using the sonic echo and transient shock methods: a thesis for the Degree of Doctor of Philosophy. - Edinburgh, 1987. - 282 p. URL: https://www.era.lib.ed.ac.uk/bitstream/handle/1842/13349/Chan19 87_001.Pdf (дата обращения 18.08.2020).

6. Jianlei L., Meng M. Analysis of the dynamic stiffness and bearing capacity for pile foundations // Vibroengineering PROCEDIA. 2015. - V. 5. - P. 134-139.

7. Liang L., Beim J. Effect of soil resistance on the low strain mobility response of piles using impulse transient response method // Proc. of the 8th International Conference on Application of Stress Wave Theory to Piling. - Lisbon, 2008. - P. 435-441. URL: http://www.pile.com/wp-content/uploads/2017/03/CH-7-066001.pdf (дата обращения 18.08.2020).

8. Капустин В.В., Чуркин А.А. Применение динамических атрибутов акустического сигнала для оценки контакта сваи с вмещающими грунтами // Вестник Московского университета. Серия 4: Геология. - 2020. - № 3. - С. 126-137.

9. Капустин В.В., Кувалдин А.В. Применение комплекса геофизических методов при исследовании фундаментных плит // Технологии сейсморазведки. - 2015. - № 1. - С. 99-105.

10. Хохлов В.К., Кандидатов И.А. Исследование влияния свойств грунта на характеристики сейсмических сигналов // Вестник МГТУ им. Баумана, сер. «Машиностроение». - 2013. - № 1. C. 23-37.

11. Заалишвили В.Б. Физические основы сейсмического микрорайонирования. - М.: Изд-во ОИФЗ РАН, 2000. - 367 с.

12. Заалишвили В.Б. Сейсмическое микрорайонирование территорий городов, населенных пунктов и больших строительных площадок. - М.: Изд-во «Наука», 2009. - 350 с.
13. Чуркин А.А., Лозовский И.Н., Жостков Р.А. Численное моделирование сейсмоакустических методов контроля качества свай // Известия Российской академии наук. Серия физическая. - 2020. - Т. 84. - № 1. - С. 124-127.

14. Физические свойства горных пород и полезных ископаемых (петрофизика). Справочник геофизика / под ред. Н.Б. Дортман. - М.: Изд-во «Недра», 1984. - 455 с.

15. Pasqual R.P.S., Kormann A.C.M. Low strain integrity tests in piles - 1-D and 3-D numerical modeling and comparisons with results obtained in the field // Multi-Science Journal. - 2019. V. 2. - P. $1-8$

16. The research of multi-defective piles for low strain testing and numerical simulation / H. Shi-Wei, H. Shi-Jian, G. Shao-Po, Y.Q. Zeng // The 2016 Structures Congress. - Korea, 2016. P. 1-8. URL: http://www.i-asem.org/publication_conf/ structures16/8.ASMM16/T3G.2.SM572_0796F1.pdf (дата обращения 18.08.2020).

17. Wang Z., Chen L., Xiao Z. Quantitative analysis of low-strain characteristics on defective piles with constriction or segregation // The Open Civil Engineering Journal. - 2015. - № 9. - P. 1-6. URL: https://benthamopen.com/contents/pdf/TOCIEJ/TOCIEJ-91.pdf (дата обращения 18.08.2020).

18. Piling engineering. 3rd ed. / K. Fleming, A. Weltman, M. Randolph, K. Elson. - UK: CRC Press, 2008. - 408 p.

19. Tomlinson M.J., Woodward J. Pile design and construction practice. 5th ed. - UK: CRC Press, 2007. - $566 \mathrm{p}$.

20. Богов С.Г. Проблемы устройства свайных оснований в городской застройке в условиях слабых грунтов Санкт-Петербурга // Интернет-журнал «Развитие городов и геотехническое строительство». - 2004. - № 8. - С. 119-128.

Поступила 29.09.2020 г.

\section{Информация об авторах}

Чуркин А.А., руководитель отдела геофизики, ООО «ЭГЕОС».

Kanycmuн B.B., кандидат физико-математических наук, младший научный сотрудник кафедры сейсмометрии и геоакустики геологического факультета Московского государственного университета им. М.В. Ломоносова.

Лозовский И.Н., научный сотрудник лаборатории магнитотеллурических исследований Центра геоэлектромагнитных исследований, филиал Института физики Земли им. О.Ю. Шмидта РАН.

Жостков Р.А., кандидат физико-математических наук, старший научный сотрудник лаборатории фундаментальных проблем экологической геофизики и вулканологии Института физики Земли им. О.Ю. Шмидта РАН. 
UDC 620.171.2:620.179.18:624.154.1:550.8.052

\title{
STUDY OF INFLUENCE OF «PILE-SOIL» SYSTEM PARAMETERS ON THE ACOUSTIC SIGNAL DYNAMIC ATTRIBUTES USING NUMERICAL MODELLING
}

\author{
Aleksei A. Churkin'1, \\ chaa92@mail.ru

\section{Vladimir V. Kapustin²,} \\ 1391854@mail.ru \\ llya N. Lozovsky3, \\ i.n.lozovsky@yandex.ru
}

\section{Ruslan A. Zhostkov 4 ,} shageraxcom@yandex.ru

\author{
1 AIGEOS LLC, \\ 8, bld. 3, Mikluho-Maklay street, Moscow, 117198, Russia. \\ 2 Lomonosov Moscow State University, \\ 1, Leninskie Gory, Moscow, 119991, Russia. \\ 3 Geoelectromagnetic Research Center, branch of the Schmidt Institute of Physics \\ of the Earth of the Russian Academy of Sciences, \\ P.O.B. 30, Moscow, Troitsk, Russia. \\ 4 Schmidt Institute of Physics of the Earth of the Russian Academy of Sciences, \\ 10, bld. 1, Bolshaya Gruzinskaya street, Moscow, 123242, Russia.
}

The relevance of the research is caused by the necessity to improve the efficiency of using non-destructive pile testing methods. The directions of research in this area are to determine the capabilities and limitations of standard approaches and to propose the new methods that allow obtaining new information about the structures. The robust estimation of pile integrity and bearing capacity obtained at the stage of quality control of the structures prior to their commissioning minimizes the subsequent risks of capital expenditures for eliminating emergency consequences. Common geophysical quality testing methods are designed to study the material of structures. The modification of the low strain impact method described in the publication suggests using additional information extracted from acoustic signals for a comparative assessment of the contact conditions of piles. This allows meeting the requirements of GOST 5686-2012 «Soils. Methods of field testing by piles» on the conducting static load tests, increasing the predictive efficiency of the complex of field tests in capital construction.

The main aim of the research is to study the general patterns in the behavior of the sonic signal dynamic attributes associated with the features of the «pile-soil» system.

Objects of the research are reinforced concrete piles and other deep foundations.

Methods: low strain impact method; attributes analysis of acoustic signal, numerical modelling of elastic waves propagation.

Results. The authors have proposed the technique for comparative assessment of contact conditions, based on the analysis of a low strain impact method signals using the dynamic attributes of the normalized spectrum square and the average-weighted frequency. Nine series of numerical models were compiled describing common "pile-soil» systems. A three-dimensional numerical simulation was performed, attributes were calculated for the obtained synthetic signals and attribute diagrams were constructed. Conclusions are drawn about the influence of changes in the parameters of the «pile-soil» system on the behavior of dynamic response attributes.

\section{Key words:}

Pile testing, low strain impact method, acoustic emission, acoustic contact, bearing capacity, numerical simulation, non-destructive testing.

\section{REFERENCES}

1. Mukhin A.A., Kapustin V.V., Churkin A.A., Lozovsky I.N Technical regulation of pile integrity testing. Geotechnics, 2019, vol. XI, no. 2, pp. 80-89. In Rus.

2. Mangushev R.A., Ponomarev A.B. For quality control issues manufacturing and acceptance of bored cast-in-place piles. Vestnik Permskogo natsionalnogo issledovatelskogo politekhnicheskogo universiteta. Stroitelstvo i arhitektura, 2014, no. 3, pp. 88-111. In Rus.

3. Kapustin V.V., Churkin A.A., Lozovsky I.N., Kuvaldin A.V. Capabilities of seismoacoustic and ultrasonic methods for quality control of pile foundations. Geotechnics, 2018, vol. X, no. 5-6, pp. 62-71. In Rus.
4. Davis A.G., Dunn C.S. From theory to field experience with the non-destructive vibration testing of piles. Proceedings of the Institution of Civil Engineers, 1974, vol. 57, pp. 571-593.

5. Chan H.F.C. Non-destructive testing of concrete piles using the sonic echo and transient shock methods. A thesis for the Degree of Doctor of Philosophy. Edinburgh, 1987. 282 p. Available at: https://www.era.lib.ed.ac.uk/bitstream/handle/1842/13349/Chan19 87_001.Pdf (accessed 18 August 2020).

6. Jianlei L., Meng M. Analysis of the dynamic stiffness and bearing capacity for pile foundations. Vibroengineering PROCEDIA, 2015, vol. 5, pp. 134-139.

7. Liang L., Beim J. Effect of soil resistance on the low strain mobility response of piles using impulse transient response method. Proc. of the $8^{\text {th }}$ International Conference on Application of Stress Wave Theory to Piling. Lisbon, 2008. pp. 435-441. Available at: 
http://www.pile.com/wp-content/uploads/2017/03/CH-7-066001.pdf (accessed 18 August 2020).

8. Kapustin V.V., Churkin A.A. Primenenie dinamicheskikh atributov akusticheskogo signala dlya otsenki kontakta svai s vmeshchayushchimi gruntami [Applying dynamic acoustic signal attributes for evaluation of contact between pile and soils]. Vestnik Moskovskogo universiteta. Seriya 4: Geologiya, 2020, no. 3, pp. 126-137.

9. Kapustin V.V., Kuvaldin A.V. Integrated geophysical approach for testing ground slabs. Tekhnologii sejsmorazvedki, 2015, no. 1, pp. 99-105. In Rus.

10. Khokhlov V.K., Kandidatov I.A. Studying the influence of soi properties on seismic signal characteristics. Vestnik MGTU im. Baumana, ser. «Mashinostroenie», 2013, no. 1, pp. 23-37. In Rus.

11. Zaalishvili V.B. Fizicheskie osnovy seysmicheskogo mikrorayonirovaniya [Physical foundations of seismic microzoning]. Moscow, OIFZ RAN Publ., 2000. 367 p.

12. Zaalishvili V.B. Seysmicheskoe mikrorayonirovanie territoriy gorodov, naselennykh punktov i bolshikh stroitelnykh ploshchadok [Seismic microzoning of cities, settlements and large construction sites]. Moscow, Nauka Publ., 2009. 350 p.

13. Churkin A.A., Lozovsky I.N., Zhostkov R.A. Chislennoe modelirovanie seysmoakusticheskikh metodov kontrolya kachestva svay [A numerical modelling of seismoacoustic pile integrity testing methods]. Izvestiya Rossiyskoy akademii nauk. Seriya fizicheskaya, 2020, vol. 84, no. 1, pp. 124-127.

14. Fizicheskie svoystva gornykh porod i poleznykh iskopaemykh (petrofizika). Spravochnik geofizika [Physical properties of rocks and minerals (petrophysics). Geophysics Handbook]. Ed. by N.B. Dortman. Moscow, Nedra Publ., 1984. 455 p.

15. Pasqual R.P.S., Kormann A.C.M. Low strain integrity tests in piles 1-D and 3-D numerical modeling and comparisons with results obtained in the field. Multi-Science Journal, 2019, vol. 2, pp. 1-8.

16. Shi-Wei H., Shi-Jian H., Shao-Po G., Zeng Y.Q. The research of multi-defective piles for low strain testing and numerical simulation. Proc. of the 2016 Structures Congress. Korea, 2016. pp. 1-8. Available at: http://www.i-asem.org/publication_conf/ structures16 /8.ASMM16/T3G.2.SM572_0796F1.pdf (accessed 18 August 2020).

17. Wang Z., Chen L., Xiao Z. Quantitative analysis of low-strain characteristics on defective piles with constriction or segregation. The Open Civil Engineering Journal, 2015, no. 9, pp. 1-6. Available at: https://benthamopen.com/contents/pdf/TOCIEJ/ TOCIEJ-9-1.pdf (accessed 18 August 2020).

18. Fleming K., Weltman A., Randolph M., Elson K. Piling engineering. $3^{\text {rd }}$ ed. UK, CRC Press, 2008. 408 p.

19. Tomlinson M.J., Woodward J. Pile design and construction practice. $5^{\text {th }}$ ed. UK, CRC Press, 2007. $566 \mathrm{p}$.

20. Bogov S.G. Problemy ustroystva svaynykh osnovaniy v gorodskoy zastroyke v usloviyakh slabykh gruntov Sankt-Peterburga [Problems of the construction of pile foundations in urban development in conditions of soft soils of St. Petersburg]. Internetzhurnal «Razvitie gorodov i geotekhnicheskoe stroitelstvo», 2004, no. 8 , pp. $119-128$.

Received: 29 September 2020.

\section{Information about the authors}

Aleksei A. Churkin, head of the Geophysical Department, AIGEOS LLC.

Vladimir V. Kapustin, Cand. Sc., junior researcher, Lomonosov Moscow State University.

Ilya N. Lozovsky, researcher, Geoelectromagnetic Research Center, branch of the Schmidt Institute of Physics of the Earth of the Russian Academy of Sciences.

Ruslan A. Zhostkov, Cand. Sc., senior researcher, Schmidt Institute of Physics of the Earth of the Russian Academy of Sciences. 